\title{
EVALUATING THE INFLUENCE OF SATELLITE OBSERVATION ON INVERSING NOx EMISSION AT REGIONAL SCALE
}

\author{
Yang Yang ${ }^{1}$, Yu Zhao ${ }^{1,2, *}$, Lei Zhang ${ }^{1}$ \\ ${ }^{1}$ State Key Laboratory of Pollution Control, Resource Reuse and School of the Environment, Nanjing University, 163 Xianlin Ave., \\ Nanjing, Jiangsu 210023, China - ahuyangyang@163.com, yuzhao@nju.edu.cn, lzhang12@nju.edu.cn \\ 2 Jiangsu Collaborative Innovation Center of Atmospheric Environment and Equipment Technology (CICAEET), Nanjing \\ University of Information Science, Technology, Jiangsu 210044, China - yuzhao@nju.edu.cn
}

\section{Commission III, WG III/8}

KEY WORDS: NOx Emissions, Top-down Estimate, Satellite Observation, YRD

\begin{abstract}
:
In order to explore the influence of satellite observation data on the top-down $\mathrm{NO}_{\mathrm{x}}$ estimates at regional scale, the top-down $\mathrm{NO}_{\mathrm{x}}$ emissions for Yangtze River Delta (YRD) region at $9 \mathrm{~km}$ spatial resolution were developed with Peking University Ozone Monitoring Instrument $\mathrm{NO}_{2}$ product (POMINO) v1 and POMINO v2 satellite observation data in January and July of 2016. The differences of top-down $\mathrm{NO}_{\mathrm{x}}$ estimates derived from the two satellites were quantitative evaluated, and the reasons were comprehensively analyzed. The total $\mathrm{NO}_{\mathrm{x}}$ emissions based on POMINO v2 in January and July was $27 \%$ and $45 \%$ higher than those derived with POMINO v1, respectively. It indicated that the difference of top-down estimate derived from different satellite observation in summer was larger than that in winter. Considering that the difference between the two observations in January was similar to that in July, it was mainly because that the sensitivity of $\mathrm{NO}_{2}$ concentration to emissions was larger in summer than in winter. Top-down estimates derived from the two satellite observation were evaluated with air quality model (AQM) and ground observation. The model performances derived from top-down NOx emission based on POMINO v1 were better than those based on POMINO v2. The probable reason was that the $\mathrm{NO}_{2}$ vertical column densities (VCD) in POMINO v1 was closer to available groundbased MAX-DOAS observations during cloudless days and the satellite observation of cloudless was usually selected to inversing $\mathrm{NO}$ emission.
\end{abstract}

\section{INTRODUCTION}

Nitrogen oxides $\left(\mathrm{NO}_{\mathrm{X}}=\mathrm{NO}_{2}+\mathrm{NO}\right)$ are important pollutants of atmosphere, and they play a key role of secondary inorganic aerosols (SIA) and $\mathrm{O}_{3}$ pollution. $\mathrm{NOx}$ emission inventory is basic data of air quality modeling and formulating pollutant control measures. The traditional bottom-up method was usually used to develop $\mathrm{NOx}$ emission inventory, and there was larger uncertainty in the bottom-up $\mathrm{NO}_{\mathrm{x}}$ emission for China due to the incomplete statistic data and emission factors (Granier et al., 2011; Ding et al., 2017; Zhao et al., 2017, Saikawa et al., 2017, Zhang et al., 2019). In order to improve the emission, top-down method was applied to constrain $\mathrm{NO}_{\mathrm{x}}$ emission with air quality model (AQM) and satellite observed troposphere $\mathrm{NO}_{2}$ vertical column density (VCD). (Kurokawa et al., 2009; de Foy et al., 2015; Zyrichidou et al., 2015; Kong et al., 2019).

The $\mathrm{NO}_{2}$ VCDs of Ozone Monitoring Instrument (OMI) was frequently used to constrain $\mathrm{NO}_{\mathrm{x}}$ emissions due to the higher temporal and spatial resolution (Zhao and Wang, 2009; Gu et al., 2014; Jena et al., 2014). The Peking University $\mathrm{OMI} \mathrm{NO}_{2}$ data product (POMINO) $\mathrm{v} 1$ and POMINO v2 derived from OMI were available in mainland China (Lin et al., 2014; Lin et al., 2015; Liu et al., 2019).

Satellite observation was essential data for top-down estimate and there was a large difference in top-down emission based on different satellite (Zhao and Wang, 2009; Gu et al., 2014). The relative difference in top-down NOx emissions derived from different satellite observations was about $32 \%$ over China in 2011 (Gu et al., 2014). The studies for exploring the influence of satellite observation were usually conducted in country level with coarse resolution, while the study for exploring the influence of different satellite observation on top-down NOx emission at the regional scale in finer resolution was lack.

In China, the air pollution usually existed at regional scale, thus the influence of different satellite observation on top-down estimates at that scale should be evaluated. Located in eastern China, the Yangtze River Delta (YRD) region including the city of Shanghai and the provinces of Anhui, Jiangsu and Zhejiang is one of the most developed regions and a hotspot of $\mathrm{NO}_{\mathrm{X}}$ emissions in the country (Li et al., 2017).

In this study, we chose YRD to explore the influence of satellite observation data on the top-down $\mathrm{NO}_{\mathrm{X}}$ estimates at the regional scale. Firstly, the $\mathrm{NO}_{2}$ VCDs of POMINO v2 for YRD at $9 \mathrm{~km}$ in January and July of 2016 were compared with those of POMINO v1. Secondly, the top-down NOx emissions of YRD in January and July of 2016 were developed with POMINO v1 and POMINO v2. Finally, the bottom-up emissions and topdown emissions of YRD derived from POMINO v1 and POMINO v2 were evaluated with AQM and ground-based observation of $\mathrm{NO}_{2}$.

\footnotetext{
* Corresponding author
} 


\section{MATERIALS AND METHODS}

\subsection{Satellite Observation}

The OMI onboard the Aura satellite cross the equator at 1:30 $\mathrm{PM}$ of local time. The Dutch Ozone Monitoring Instrument $\mathrm{NO}_{2}$ product (DOMINO) v2 was derived by Boersma et al. (2011) base on OMI data. Lin et al. (2014) developed the improved Peking University Ozone Monitoring Instrument $\mathrm{NO}_{2}$ product (PMONINO) v1 for China based on DOMINO v2 algorithm (OMI $\mathrm{NO}_{2}$ slant columns and stratospheric correction) and a more sophisticated air mass factor (AMF) calculation over China. Liu et al. (2019) developed an improved POMINO v2 for China upon DOMINO v2 with optimizing vertical profiles of $\mathrm{NO}_{2}$. In order to explore the influence of satellite observation on top-down $\mathrm{NO}_{\mathrm{X}}$ emission of YRD, the level 2 data of both POMINO v1 and POMINO v2 were used. The original spatial resolution of OMI was $24 \times 13 \mathrm{~km}$ at nadir (Levelt et al., 2006). For matching the resolution of the model, the $\mathrm{NO}_{2} \mathrm{VCD}$ of POMINO v1 and POMINO v2 were resampled into $18 \times 18 \mathrm{~km}$ grid with the area weight method, and then they were downscaled to $9 \times 9 \mathrm{~km}$ with Kriging interpolation method.

\subsection{Inverse Approach}

The nonlinear inverse approach was used to constrain the $\mathrm{NO}_{\mathrm{X}}$ emission in this study. In this approach, the variable nonlinear correlation between $\mathrm{NO}_{2} \mathrm{VCDs}$ and $\mathrm{NOx}$ emissions, and the top-down emissions were calculated based on the following equations:

$$
\begin{aligned}
& E_{t}=E_{a}\left(1+\frac{\Omega_{o}-\Omega_{a}}{\Omega_{o}} \beta\right) \\
& \frac{\Delta E}{E}=\beta \frac{\Delta \Omega}{\Omega}
\end{aligned}
$$

where $E_{t}=$ the top-down emissions;

$E_{a}=$ the a priori emissions;

$\Omega_{o}=$ the observed $\mathrm{NO}_{2} \mathrm{VCD}$;

$\Omega_{a}=$ the modeled $\mathrm{NO}_{2} \mathrm{VCD} ;$

$\beta=$ the response coefficient of the simulated $\mathrm{NO}_{2} \mathrm{VCD}$ to a certain change in emissions.

By testing, it was reasonable that the $10 \%$ was set as the changed fraction of a priori emissions in this work, and $\beta$ was estimated based on the changed fraction of the a priori emission and corresponding changed modeled $\mathrm{NO}_{2} \mathrm{VCD}$. The daily topdown emission derived with the nonlinear approach was treated as the a priori emission of the next day. According to the testing based on the method used in the Cooper et al. (2017), the topdown NOx emission was usually improved by the constraining of each time in a month. Therefore, we used the average of topdown $\mathrm{NO}_{\mathrm{X}}$ of the last three days as the top-down $\mathrm{NO}_{\mathrm{X}}$ of the moth.

\subsection{Model Configuration}

The Models-3 Community Multi-scale Air Quality (CMAQ) version 4.7.1 was applied to constrain and evaluate the $\mathrm{NOx}$ emissions. As illustrated in Figure 1, two nested domains were applied with the spatial resolutions at 27 and $9 \mathrm{~km}$, respectively in the Lambert Conformal Conic projection centered at $\left(110^{\circ} \mathrm{E}\right.$, $\left.34^{\circ} \mathrm{N}\right)$. The mother domain (D1, $177 \times 127$ cells) covered most parts of China, North and South Korea, and few parts of Japan, while the second $(\mathrm{D} 2,118 \times 121$ cells $)$ covered the whole YRD region. Details on model configuration were described in Zhou et al. (2017) and Yang and Zhao (2019). The spin-up period was 5 days in this study. The boundary condition of D1 was taken from clean air, and that of D2 was taken from the results of AQM in D1.

The emissions of anthropogenic origin in D1 and D2 were obtained from Multi Resolution Emission Inventory for China (MEIC) for 2015. Biogenic emissions were from the Model Emissions of Gases and Aerosols from Nature developed under the Monitoring Atmospheric Composition and Climate project (MEGAN MACC, Sindelarova et al., 2014), and the emissions of $\mathrm{Cl}, \mathrm{HCl}$ and lightning $\mathrm{NOx}$ were from the Global Emissions Initiative (GEIA, Price et al., 1997). The NOx emissions from soil were collected from Yienger and Levy (1995), and were doubled as suggested by Zhao and Wang (2009) and Lin et al. (2010). Meteorological fields were provided by the Weather Research and Forecasting Model (WRF) version 3.4, and the outputs were transferred by meteorology chemistry interface professor (MCIP) version 4.2 into the chemistry transport module in CMAQ (CCTM). The ground-based $\mathrm{NO}_{2}$ observations were used to evaluate the bottom-up and top-down $\mathrm{NO}$ emissions in January and July 2016. The hourly $\mathrm{NO}_{2}$ concentrations of 156 stations in 36 cities of YRD were obtained from the China National Environmental Monitoring Center (http://www.cnemc.cn/).

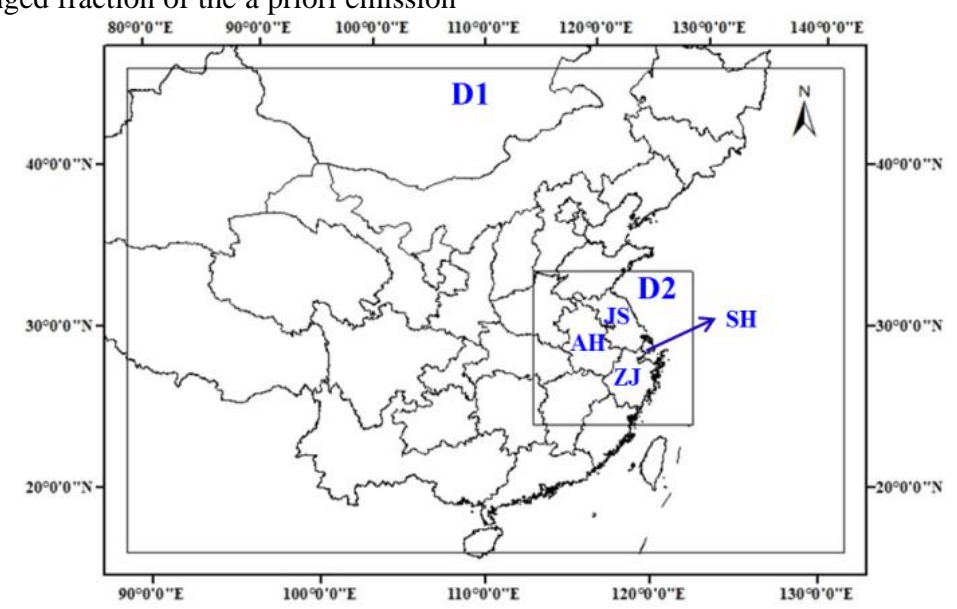

Figure 1. Model domain (AH, JS, ZJ and SH indicate Anhui, Jiangsu and Zhejiang provinces and Shanghai city) 
(a) January 2016

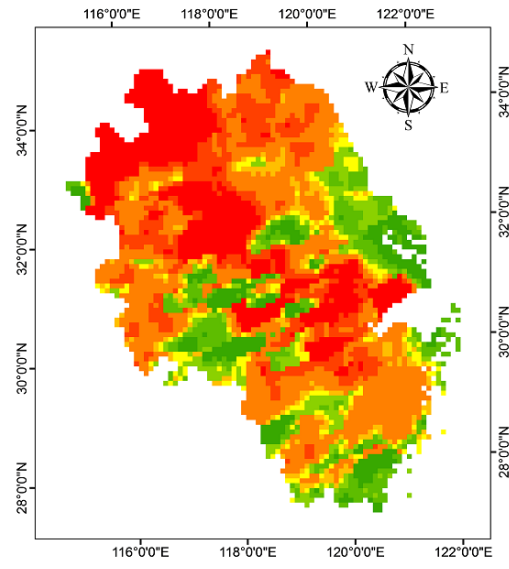

POMINO v2 - POMINO v1

NMB:27.4\% NME:36.7\% (b) July 2016

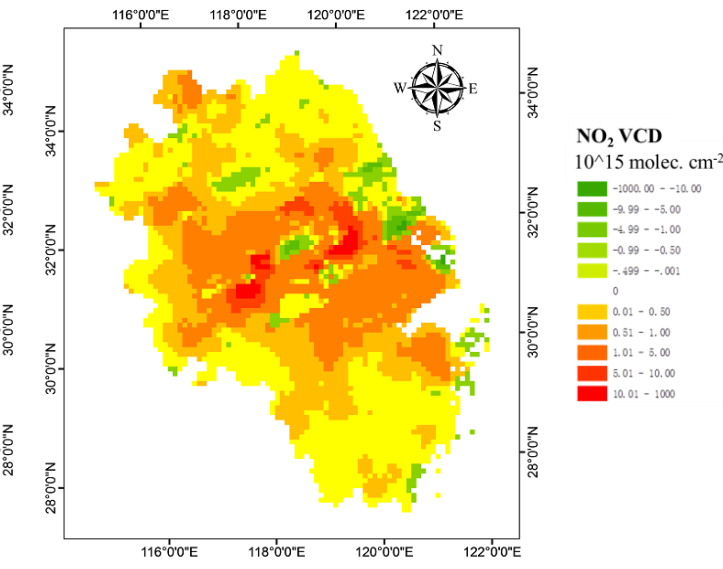

POMINO v2 - POMINO v1

NMB:34.6\% NME:36.3\%

Figure 2. The differences (POMINO v2 - POMINO v1) of $\mathrm{NO}_{2}$ VCD derived from POMINO v2 and POMINO v1 in January and July 2016.

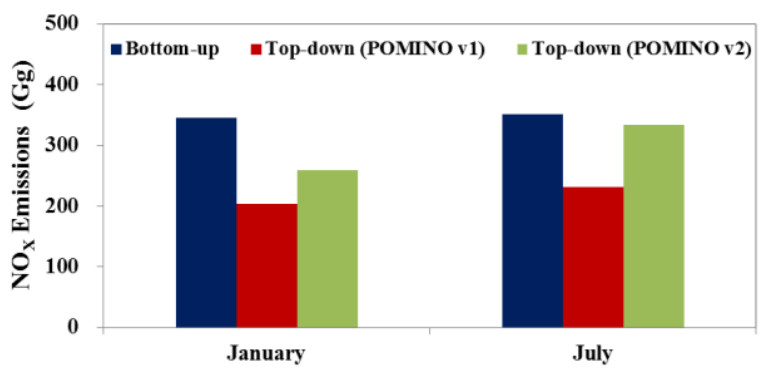

Figure 3. The bottom-up total NOx emission and top-down ones derived from POMINO v2 and POMINO v1 in January and July 2016.

(a) January 2016

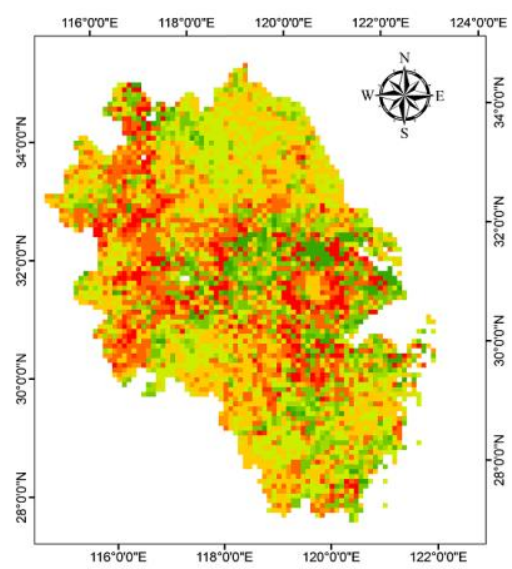

POMINO v2 - POMINO v1

NMB:26.7\% NME: $117.7 \%$ (b) July 2016

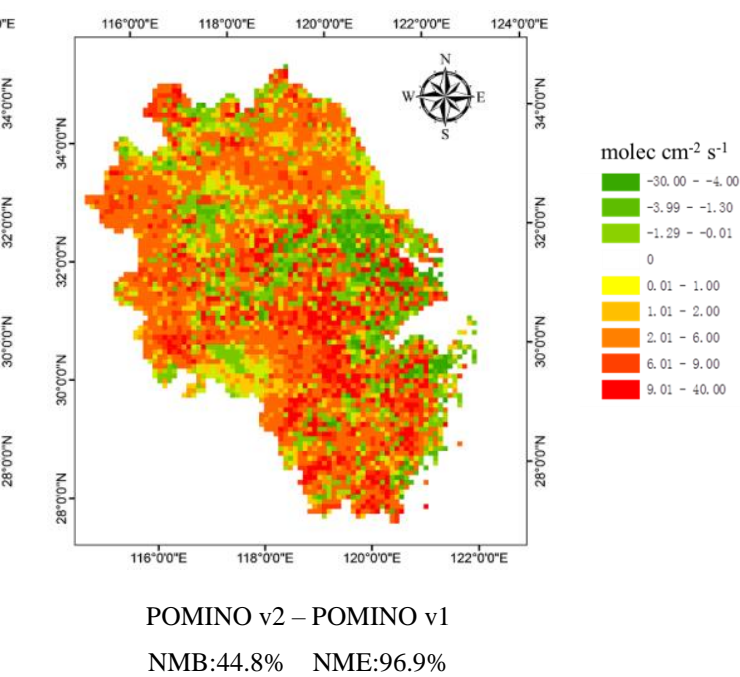

Figure 4. The spatial differences (POMINO v2 - POMINO v1) of top-down NOx emissions derived from POMINO v2 and POMINO v1 in January and July 2016. 


\section{RESULTS AND DISCUSSION}

\subsection{Comparison of Satellite Observation}

The differences (POMINO v2 - POMINO v1) of $\mathrm{NO}_{2} \mathrm{VCD}$ for YRD derived from POMINO v2 and POMINO v1 in January and July 2016 are shown in Figure 2, and the normalized mean biases (NMB) and normalized mean errors (NME) were calculated with the equations $\mathrm{A} 1$ and $\mathrm{A} 2$ in Appendix. In general, the $\mathrm{NO}_{2}$ VCDs of YRD derived from POMINO v2 were $27.4 \%$ and $34.6 \%$ higher than those derived from POMINO v1 in January and July, respectively. Specifically, the $\mathrm{NO}_{2}$ VCDs of POMINO v2 were higher than those of POMINO $\mathrm{v} 1$ in mostly of YRD except south-east of Jiangsu, north of Shanghai and south of Anhui and Zhejiang in January 2016. For July, the $\mathrm{NO}_{2}$ VCDs of POMINO v2 were higher than those of POMINO $\mathrm{v} 1$ in almost all regions of YRD. The degree of spatial difference between POMINO v2 and POMINO v1 in January was similar to that in July, resulting from the similar NME derived from $\mathrm{NO}_{2}$ VCDs of POMINO v2 and POMINO v1.

\subsection{Comparison of the Top-down Emissions}

The bottom-up total NOx emissions and top-down ones derived from POMINO v2 and POMINO v1 in January and July 2016 are shown in Figure 3. The top-down estimates derived POMNIMO v1 and POMINO v2 were smaller than the a priori emissions for the two months, implying that current bottom-up emissions might be overestimated. The average monthly emissions of the top-down estimation based on POMINO v1 and POMINOv2 were calculated at 218 and $297 \mathrm{Gg} / \mathrm{month}$, $37 \%$ and $15 \%$ smaller than those from the a priori emission. The bottom-up NOx emissions and top-down NOx emissions derived from POMINOv1 and POMINOv2 in July were 1.6\%, $13.6 \%$ and $28.7 \%$ larger than those of January, respectively. It indicated that the seasonal variation of NOx emissions probably be underestimated in the bottom-up emission inventory. The total $\mathrm{NO}_{\mathrm{x}}$ emissions based on POMINO v2 in January and July was $27 \%$ and $45 \%$ higher than those derived with POMINO v1, respectively. Considering that the relatively smaller difference $(7.2 \%)$ between NMB derived from two observations in January (27.4\%) and that in July (34.6\%), it was mainly because that the sensitivity of $\mathrm{NO}_{2}$ concentration to $\mathrm{NO}_{\mathrm{X}}$ emissions was larger in summer than in winter.

The spatial differences (POMINOv2 - POMINO v1) of NOx emissions derived from POMINO v2 and POMINO v1 in January and July 2016 are shown in Figure 4. The spatial differences of top-down $\mathrm{NO}_{\mathrm{x}}$ emissions derived from POMINO v2 and POMINO v1 were similar to those of $\mathrm{NO}_{2} \mathrm{VCD}$. The top-down NOx emissions in most of YRD based on POMINO v2 were higher than those of POMINO v1 in January and July. It suggested that the differences of top-down $\mathrm{NO}_{\mathrm{X}}$ emission between POMINO v1 and POMINO v2 were mainly associated with the differences of $\mathrm{NO}_{2} \mathrm{VCD}$ between the two satellite observations.

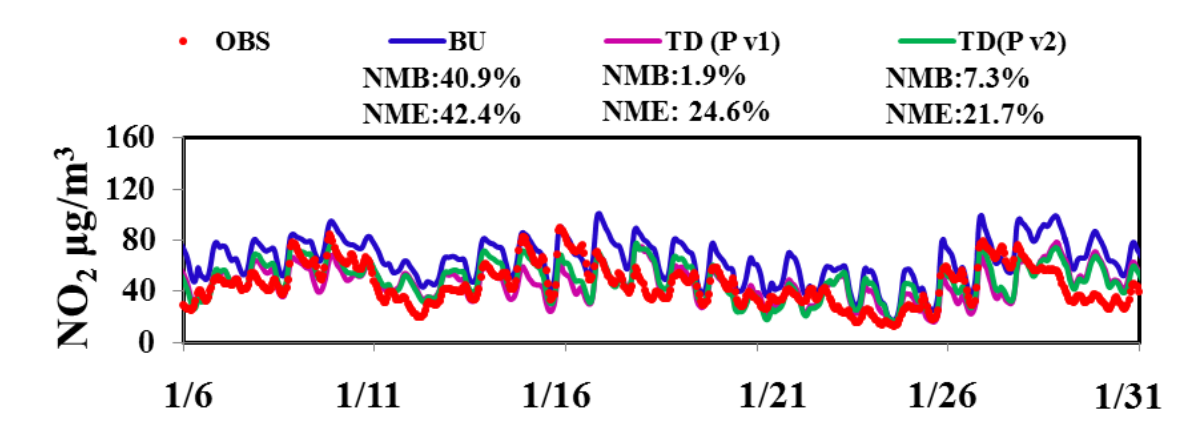

(a) January 2016

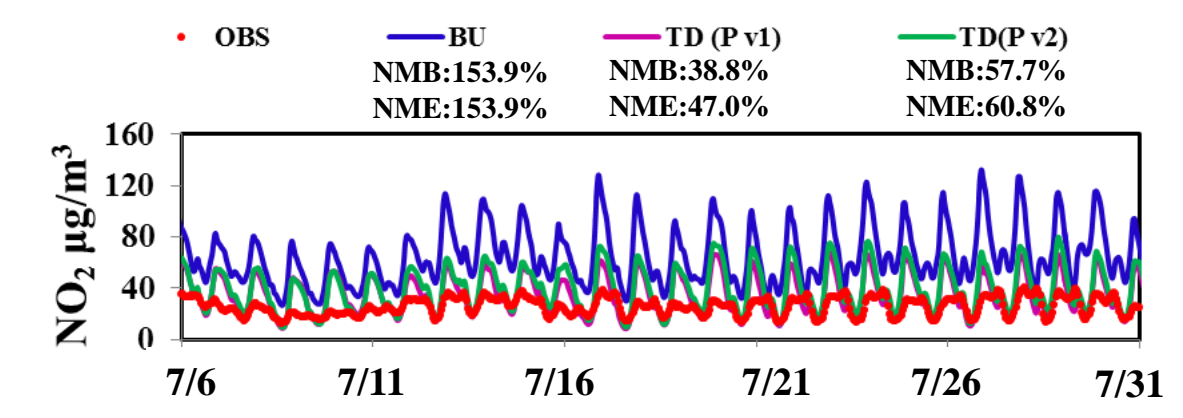

(b) July 2016

Figure 5. The observed and simulated $\mathrm{NO}_{2}$ concentrations derived from bottom-up (BU) NOx emissions and top-down (TD) NOx emissions based on POMINO v2 (P v2) and POMINO v1 (P v1) in January and July 2016. 
(a) January 2016

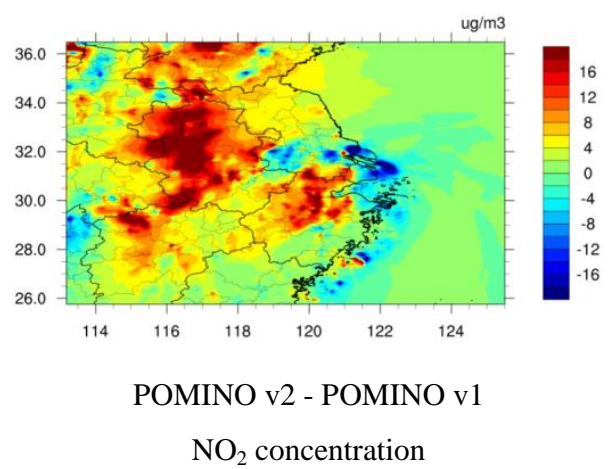

(b) July 2016

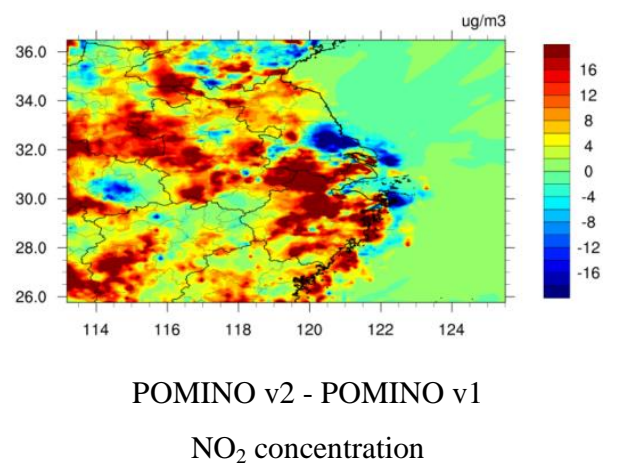

Figure 6. The spatial differences (POMINO v2 - POMINO v1) of $\mathrm{NO}_{2}$ concentrations derived from top-down NOx emissions based on POMINO v2 and POMINO v1 in January and July 2016.

\subsection{Evaluation with AQM and Ground Observation}

The observed and simulated $\mathrm{NO}_{2}$ concentrations derived bottom-up $\mathrm{NO}_{\mathrm{x}}$ emissions and top-down $\mathrm{NO}_{\mathrm{x}}$ emissions based on POMINO v2 and POMINO v1 in January and July 2016 are shown in Figure 5. In general, the $\mathrm{NO}_{2}$ concentrations derived from bottom-up emissions were largely higher than those of observed ones in January and July, implying that the bottom-up NOx emissions were probably overestimated. The simulated $\mathrm{NO}_{2}$ concentrations derived from top-down $\mathrm{NO}_{\mathrm{x}}$ emissions of POMINO v1 and POMINO v2 were closer to observed ones than those of bottom-up ones, resulting from the smaller NMB and NME derived from simulated and observed $\mathrm{NO}_{2}$ concentrations. It indicated that the top-down $\mathrm{NO}_{\mathrm{x}}$ emissions were improved by top-down estimates based on the POMINO $\mathrm{v} 1$ and POMINO v2. Moreover, the improvements in the model performance of top-down $\mathrm{NO}_{\mathrm{x}}$ emissions in July were largely higher than those in January, and it was mainly because of higher response coefficient between $\mathrm{NO}_{2}$ concentrations and $\mathrm{NO}_{\mathrm{x}}$ emissions.

The model performances derived from top-down $\mathrm{NO}_{\mathrm{x}}$ emission based on POMINO v1 were better than those based on POMINO v2. The probable reason was that the $\mathrm{NO}_{2} \mathrm{VCD}$ in POMINO v1 was closer to available ground-based MAXDOAS observations during cloudless days and the satellite observation of cloudless was usually selected to inversing NOx emission (Liu et al., 2019).

The spatial differences of $\mathrm{NO}_{2}$ concentration derived from topdown NOx emissions based on POMINO v2 and POMINO v1 in January and July 2016 are shown in Figure 6. The spatial differences of $\mathrm{NO}_{2}$ concentrations derived from top-down emissions based on POMNINO v2 and POMINO v1 were similar to those of top-down emissions.

\section{CONCLUSIONS}

Taking the YRD region in China as examples, we have developed the top-down estimates of $\mathrm{NO}_{\mathrm{X}}$ emissions based on POMINO v1 and POMINO v2 and evaluated the bottom-up and satellite-derived top-down estimates of emissions in YRD in January and July 2016.

The total NOx emissions based on POMINO v2 in January and July was $27 \%$ and $45 \%$ higher than those derived with POMINO $v 1$, respectively. It indicated that the difference of top-down estimate derived from different satellite observation in summer was larger than that in winter. Considering that the relatively smaller difference $(7.2 \%)$ between $\mathrm{NMB}$ derived from two observations in January $(27.4 \%)$ and that in July $(34.6 \%)$, it was mainly because that the sensitivity of $\mathrm{NO}_{2}$ concentration to $\mathrm{NO}_{\mathrm{x}}$ emissions was larger in summer than in winter.

The model performances derived from top-down $\mathrm{NO}_{\mathrm{x}}$ emission based on POMINO v1 were better than those based on POMINO v2. It suggested that the top-down estimates based on POMINO v1 were closer to real ones than those based on POMINO v2. The probable reason was that the $\mathrm{NO}_{2} \mathrm{VCD}$ of POMINO v1 was closer to available ground-based MAXDOAS observations during cloudless days and the satellite observation of cloudless was usually selected to inversing $\mathrm{NO}$ emission.

\section{ACKNOWLEDGEMENTS}

This work was sponsored by Natural Science Foundation of China (91644220 and 41575142) and the National Key Research and Development Program of China (2017YFC0210106). We would also like to appreciate Tsinghua University for free use of national emission data (MEIC), and Peking University for the support of satellite data (POMINO v1 and POMINO v2, respectively).

\section{REFERENCES}

Boersma, K.F., Eskes, H.J., Dirksen, R.J., van der A, R.J., Veefkind, J.P., Stammes, P., Huijnen, V., Kleipool, Q.L., Sneep, M., Claas, J., Leitao, J., Richter, A., Zhou, Y., Brunner, D., 2011. An improved retrieval of tropospheric $\mathrm{NO}_{2}$ columns from the ozone monitoring instrument, Atmospheric Measurement Techniques, 4, 1905-1928.

Cooper, M., Martin, R. V., Padmanabhan, A., Henze, D. K., 2017. Comparing mass balance and adjoint methods for inverse modeling of nitrogen dioxide columns for global nitrogen oxide emissions. Journal of Geophysical Research: Atmospheres, 122, 4718-4734.

de Foy, B., Lu, Z., Streets, D.G., Lamsal, L.N., Duncan., B.N., 2015. Estimates of power plant NOx emissions and lifetimes from $\mathrm{OMI} \mathrm{NO}_{2}$ satellite retrievals. Atmospheric Environment, $116,1-11$. 
Ding, J.Y. Miyazaki, K., van der, R.J., Mijling, B., Kurokawa, J., Cho, S.Y., Greet Janssens-Maenhout, G., Zhang, Q., Liu, F., Levelt, P.F., 2017. Intercomparison of $\mathrm{NO}_{\mathrm{X}}$ emission inventories over East Asia. Atmospheric Chemistry and Physics, 17, 10125-10141.

Granier, C., Bessagnet, B., Bond, T., Angiola A.D., van der G.H.D. , Frost G.J. , Heil A., Kaiser J.W., Kinne S., Klimont Z., Kloster S., Lamarque J.F., Liousse C., Masui T., Meleux, F., Mieville, A., Ohara, T., Raut, J.C., Riahi, K., Schultz, M.G., Smith, S.J., Thompson, A., van Aardenne, J., van der Werf, G.R., van Vuuren, D.P., 2011. Evolution of anthropogenic and biomass burning emissions of air pollutants at global and regional scales during the 1980-2010 period. Climatic Change, 109, 163-190.

Gu D.S., Wang Y.H., Yin R., Zhang Y.Z, Smeltzer C., 2016. Inverse modelling of NOx emissions over eastern China: uncertainties due to chemical non-linearity. Atmospheric Measurement Techniques, 9, 5193-5201.

Kong, H., Lin J.T., Zhang, R.X., Liu, M.Y., Weng, H.J., Ni, R.J., Chen, L.L., Wang, J.X., Zhang, Q., 2019. High-resolution $\left(0.05^{\circ} \times 0.05^{\circ}\right)$ NOx emissions in the Yangtze River Delta inferred from OMI. Atmospheric Chemistry and Physics Discuss, in review.

Kurokawa, J.I., Yumimoto, K., Uno, I., Ohara, T., 2009. Adjoint inverse modeling of NOx emissions over eastern China using satellite observations of $\mathrm{NO}_{2}$ vertical column densities. Atmospheric Environment, 43, 1878-1887.

Levelt, P.F., Hilsenrath, E., Leppelmeier, G.W., van den Oord, G.H.J., Bhartia, P.K., Tamminen, J., de Haan, J.F., Veefkind, J.P., 2006. Science objectives of the ozone monitoring instrument. IEEE Transactions on Geoscience and Remote Sensing, 44, 1199-1208.

Li, M., Zhang, Q., Kurokawa, J.i., Woo, J.H., He, K., Lu, Z., Ohara, T., Song, Y., Streets, D.G., Carmichael, G.R., Cheng, Y. Hong, C., Huo, H., Jiang, X., Kang, S., Liu, F., Su, H., Zheng, B., 2017. MIX: a mosaic Asian anthropogenic emission inventory under the international collaboration framework of the MICS-Asia and HTAP. Atmospheric Chemistry and Physics, 17, 935-963.

Lin, J.T., McElroy, M.B., Boersma, K.F., 2010. Constraint of anthropogenic $\mathrm{NO}_{\mathrm{x}}$ emissions in China from different sectors: a new methodology using multiple satellite retrievals. Atmospheric Chemistry and Physics, 10, 63-78.

Lin, J.T., Martin, R.V., Boersma, K.F., Sneep, M., Stammes, P., Spurr, R., Wang, P., Van Roozendael, M., Clémer, K., Irie, H., 2014. Retrieving tropospheric nitrogen dioxide from the ozone monitoring instrument: Effects of aerosols, surface reflectance anisotropy, and vertical profile of nitrogen dioxide. Atmospheric Chemistry and Physics, 14, 1441-1461.

Lin, J.T., Liu, M.Y., Xin, J.Y., Boersma, K.F., Spurr, R., Martin, R., Zhang, Q., 2015. Influence of aerosols and surface reflectance on satellite $\mathrm{NO}_{2}$ retrieval: seasonal and spatial characteristics and implications for NOx emission constraints. Atmospheric Chemistry and Physics, 15, 11217-11241.
Liu, M.Y., Lin, J.T., Boersma, K.F., Pinardi, G., Wang, Y., Chimot, J., Wagner, T., Xie, P., Eskes, H., Van Roozendael, M., Hendrick, F., Wang, P., Wang, T., Yan, Y.Y., Chen, L.L., Ni, R.J., 2019. Improved aerosol correction for OMI tropospheric $\mathrm{NO}_{2}$ retrieval over East Asia: constraint from CALIOP aerosol vertical profile, Atmospheric Measurement Techniques 12, 1-21. Jena, C., Ghude, S.D, Beig, G., Chate, D.M., Kumar, R, Pfister, G.G., Lal, D.M., Surendran, D.E., Fadnavis, S., van der A, R.J., 2014. Inter-comparison of different $\mathrm{NO}_{\mathrm{X}}$ emission inventories and associated variation in simulated surface ozone in Indian region, Atmospheric Environment, 17, 61-73.

Price, C., Penner, J., Prather, M., 1997. NOx from lightning, Part I: Global distribution based on lightning physics. Journal of Geophysical Research-Atmospheres, 102(D5), 5929-5941.

Saikawa E., Kim H., Zhong M., Zhao Y., Janssens-Maenhout G., Kurokawa J., Klimont Z., Wagner F., Naik V., Horowitz L.W., Zhang Q., 2017. Comparison of emissions inventories of anthropogenic air pollutants and greenhouse gases in China. Atmospheric Chemistry and Physics, 17, 6393-6421.

Sindelarova, K., Granier, C., Bouarar, I., Guenther, A., Tilmes, S., Stavrakou, T., Müller, J.-F., Kuhn, U., Stefani, P., Knorr, W., 2014. Global data set of biogenic VOC emissions calculated by the MEGAN model over the last 30 years. Atmospheric Chemistry and Physics, 14, 9317-9341.

Yang, Y. Zhao, Y., 2019. Quantification and evaluation of atmospheric pollutant emissions from open biomass burning with multiple methods: A case study for Yangtze River Delta region, China. Atmospheric Chemistry and Physics, 19, 327-348.

Yienger, J.J., H. Levy II, 1995. Empirical model of global soil biogenic NOX emissions. Journal of Geophysical Research, $100,11447-11464$

Zhang Y, Bo X, Zhao Y, Nielsen, C.P., 2019. Benefits of current and future policies on emission reduction from China's coal-fired power sector indicated by continuous emission monitoring. Environmental Pollution, 251: 415-424.

Zhao, C., and Wang Y., 2009. Assimilated inversion of $\mathrm{NO}_{\mathrm{X}}$ emissions over east Asia using $\mathrm{OMI} \mathrm{NO}_{2}$ column measurements. Geophysical Research Letters, 36(6), 1-5.

Zhao, Y., Zhou, Y.D., Qiu, L.P. Zhang, J., 2017, Quantifying the uncertainties of China's emission inventory for industrial sources: From national to provincial and city scales. Atmospheric Environment, 165, 207-221.

Zhou, Y. D., Zhao Y., Mao P., Zhang Q, Zhang J., Qiu, L. P., Yang, Y., 2017. Development of a high-resolution emission inventory and its evaluation and application through air quality modeling for Jiangsu Province, China. Atmospheric Chemistry and Physics, 17, 211-233.

Zyrichidou, I., Koukouli, M.E., Balis, D., Markakis, K., Poupkou, A., Katragkou, E., Kioutsioukis, I., Melas, D., Boersma, K.F., van Roozendael, M., 2015. Identification of surface $\mathrm{NO}_{\mathrm{x}}$ emission sources on a regional scale using OMI $\mathrm{NO}_{2}$. Atmospheric Environment, 101, 82-93. 


\section{APPENDIX}

The NMB and NME between variable A and variable B were calculated based on the following equations:

$$
\begin{array}{r}
N M B=\frac{\sum_{i=1}^{n}\left(A_{i}-B_{i}\right)}{\sum_{i=1}^{n}\left(B_{i}\right)} \times 100 \% \\
N M E=\frac{\sum_{i=1}^{n}\left|A_{i}-B_{i}\right|}{\sum_{i=1}^{n}\left(B_{i}\right)} \times 100 \%
\end{array}
$$

where $n=$ the number of elements in $\mathrm{A}$ and $\mathrm{B}$. 